\author{
Milou P. H. Busard \\ Velja Mijatovic \\ Cees van Kuijk \\ Peter G. A. Hompes \\ Jan Hein T. M. van Waesberghe
}

\title{
Appearance of abdominal wall endometriosis on MR imaging
}

Received: 20 July 2009

Revised: 5 October 2009

Accepted: 14 October 2009

Published online: 21 November 2009

(C) The Author(s) 2009.

This article is published with open access at Springerlink.com

M. P. H. Busard $(\bowtie) \cdot$ C. van Kuijk ·

J. H. T. M. van Waesberghe

Department of Radiology,

Endometriosis Center VUMC,

VU Medical Center,

De Boelelaan 1117,

1081 HV Amsterdam, The Netherlands

e-mail: m.busard@vumc.nl

Tel.: +31-204-442333

Fax: +31-204-440317

V. Mijatovic · P. G. A. Hompes

Department of Gynecology,

Endometriosis Center,

VU Medical Center,

Amsterdam, The Netherlands
Abstract Objective: Abdominal wall endometriosis (AWE) is defined as endometrial tissue that is superficial to the peritoneum. AWE is often difficult to diagnose, mimicking a broad spectrum of diseases. The aim of this study was to describe the appearance of AWE on magnetic resonance (MR) imaging.

Methods: We present ten patients with AWE (12 lesions) in which MR imaging was used for diagnosis. MR imaging included T2-weighted imaging and T1-weighted imaging with fat suppression. To assess the value of diffusion-weighted imaging (DWI) in endometriosis, four patients underwent additional DWI. The apparent diffusion coefficient (ADC) was calculated using $b$ values of 50, 400, 800 and $1,200 \mathrm{~s} / \mathrm{mm}^{2}$. Results: In most cases, the lesion was located ventral or dorsal to the aponeurosis of the rectus oblique muscle $(n=6)$ or in the rectus abdominis $(n=5)$. MR of AWE lesions showed isointense or slightly hyperintense signal compared with muscle on T2-weighted images and showed isointense or slightly hyperintense signal compared with muscle on T1-weighted images with foci of high signal intensity, indicative of haemorrhage. The mean ADC value of AWE was $0.93 \times 10^{-3} / \mathrm{mm}^{2} / \mathrm{s}$. Conclusion: MR imaging seems to be useful in determining the location and depth of infiltration in surrounding tissue preoperatively.

Keywords Abdominal wall endometriosis · Endometriosis · Surgical scars $\cdot$ Magnetic resonance imaging $\cdot$ Diffusion-weighted imaging

\section{Introduction}

Abdominal wall endometriosis (AWE) is a common site of extra-pelvic endometriosis usually developing in a surgical abdominal scar with an incidence of $0.1 \%$ [1]. The most common presentation is an abdominal wall mass associated with pain during menstruation. The differential diagnosis includes hernias, lipomas, sebaceous cysts, as well as malignant tumours [2]. Malignant degeneration has been reported, although very rare [3-6].

In the last decade various imaging techniques have been assessed for their value, including ultrasound (US), USguided fine-needle aspiration (FNA), computed tomography (CT) and magnetic resonance (MR) imaging.
US findings are often non-specific, and a wide spectrum of disorders presenting as a mass in the abdominal wall should be considered in the imaging differential diagnosis [7].

US-guided FNA can be a useful, less-invasive method of confirming abdominal wall endometriosis. The sample may show tubular structures indicative of endometrial tissue and stromal cells indicative of endometriosis $[1,8,9]$. However, the results are often inconclusive, because of a limited amount of material that may be sampled as well as fibrotic tissue being present in endometriosis [10-12]. In the study of Zhao et al. [11], FNA was inconclusive in $75 \%$ of cases. CT should not be used for the detection of AWE, because of its lack of contrast resolution and its radiation exposure [13]. 
At this moment, to our knowledge, several case reports and a few cohorts, up to eight patients using MR imaging in AWE, have been described in the literature [1, 7, 14-17]. In these studies, endometriosis appeared homogeneously hypointense or isointense, or heterogeneous with focal areas of high and low signal intensity, suggesting old haemorrhage or fibrosis on T2-weighted and T1-weighted fat-suppressed imaging.

Recent developments in MR imaging make it possible to obtain reliable diffusion-weighted images of the abdomen. In addition, diffusion-weighted imaging (DWI) may be useful for differentiating tumours according to their different cellular construction [18]. Regarding endometrial cysts, previous studies found a tendency towards lower apparent diffusion coefficient (ADC) values compared with other pelvic cysts, which might be more closely related to blood concentration [19-21]. Intracystic blood clots floating in or attached to the wall of endometrial cysts showed a mean value of $1.11 \times 10^{-3} / \mathrm{mm}^{2} / \mathrm{s}$ [22]. To our knowledge, however, no previous studies exist describing DWI in deep infiltrating endometriosis (DIE), including AWE.

We present ten patients with AWE, the largest group presented in the literature, in which MR imaging, including DWI in four patients, was used for the evaluation of suspected or proven AWE.

\section{Materials and methods}

\section{Patient population}

Between March 2007 and March 2009, ten out of 246 consecutive patients visiting our outdoor MR clinic for the analysis of suspected or known deep infiltrating endometriosis, were diagnosed with AWE. Suspicion of AWE

Table 1 Patients' clinical characteristics (GnRH agonist gonadotrophin-releasing hormone, $O A C$ oral anti-contraceptive, IUD intrauterine device, $S C$ Caesarean section, NSAID non-steroidal anti-inflammatory drug)

\begin{tabular}{|c|c|c|c|c|c|}
\hline $\begin{array}{l}\text { Patient } \\
\text { number }\end{array}$ & Age & Clinical presentation & Previous surgery and incision & Location & Therapy/ follow-up \\
\hline 1 & 37 & Cyclic pain & $\begin{array}{l}\text { Diagnostic laparoscopy: } \\
\text { bladder wall } \\
\text { endometriosis } \\
\text { trocar insertion scar }\end{array}$ & Right corner of trocar scar & $\begin{array}{l}\text { Surgical excision (histology: } \\
\text { endometriosis) }\end{array}$ \\
\hline 2 & 31 & $\begin{array}{l}\text { Cyclical pain }+ \text { increased } \\
\text { lesion size }\end{array}$ & No scar & Right groin region & $\begin{array}{l}\text { Surgical excision (histology: } \\
\text { endometriosis) }\end{array}$ \\
\hline 3 & 33 & $\begin{array}{l}\text { Infiltration/ infection of } \\
\text { SC scar, no pain } \\
\text { symptoms }\end{array}$ & $\begin{array}{l}\text { Emergency SC } \\
\text { median incision }\end{array}$ & $\begin{array}{l}\text { Caudal corner of medial } \\
\text { incision }\end{array}$ & $\begin{array}{l}\text { Antibiotics and OAC } \\
\text { continuous }\end{array}$ \\
\hline 4 & 30 & Cyclical pain & $\begin{array}{l}\text { Laparotomical cystectomy } \\
\text { right ovary } \\
\text { Pfannenstiel }\end{array}$ & $\begin{array}{l}\text { Left corner of laparotomy } \\
\text { scar }\end{array}$ & $\begin{array}{l}\text { Pain medication, no hormonal } \\
\text { treatment, because of wanted } \\
\text { pregnancy }\end{array}$ \\
\hline 5 & 40 & Cyclical pain & $\begin{array}{l}\text { SC } \\
\text { Pfannenstiel }\end{array}$ & $\begin{array}{l}\text { No specific findings } \\
\text { (examination may be } \\
\text { limited because of } \\
\text { adiposity) }\end{array}$ & OAC continuous \\
\hline 6 & 40 & Cyclical pain & $\begin{array}{l}\text { SC (3) } \\
\text { Pfannenstiel }\end{array}$ & $\begin{array}{l}2 \text { lesions: right and left } \\
\text { corner of SC scar }\end{array}$ & OAC continuous \\
\hline 7 & 21 & $\begin{array}{l}\text { Cyclical pain, cyclical } \\
\text { increase in lesion size }\end{array}$ & No scar & Left groin region & $\begin{array}{l}\text { Surgical excision (histology: } \\
\text { endometriosis) }\end{array}$ \\
\hline 8 & 37 & Progressive cyclical pain & $\begin{array}{l}\text { SC } \\
\text { Pfannenstiel }\end{array}$ & Right side of SC scar & OAC continuous \\
\hline 9 & 36 & $\begin{array}{l}\text { Continuous pain } \\
\text { symptoms }\end{array}$ & $\begin{array}{l}\text { Laparotomy, because of } \\
\text { chronic appendicular } \\
\text { inflammation } \\
\text { median laparotomy scar }\end{array}$ & $\begin{array}{l}\text { Median laparotomy scar, } \\
\text { also hernia of abdominal } \\
\text { fat }\end{array}$ & $\begin{array}{l}\text { GnRH agonist, surgical } \\
\text { excision planned }\end{array}$ \\
\hline 10 & 28 & Cyclical pain & $\begin{array}{l}\text { SC } \\
\text { Pfannenstiel }\end{array}$ & $\begin{array}{l}2 \text { lesions: left corner of SC } \\
\text { scar and medial from } 1 \mathrm{st} \\
\text { lesion }\end{array}$ & $\begin{array}{l}\text { OAC not effective, surgical } \\
\text { excision planned }\end{array}$ \\
\hline
\end{tabular}


was raised because of pain symptoms related to the menstrual period or continuously, location in or close to a scar and ultrasound appearance. Eight patients had a history of previous abdominal surgery, including Caesarean section $(n=5)$, diagnostic laparoscopy $(n=1)$, and laparotomy $(n=2)$. Two out of these eight patients were diagnosed with pelvic endometriosis before diagnosis of AWE.

\section{MR imaging technique}

MR imaging of the pelvis was performed at 1.5 Tesla (Avanto or Sonata, Siemens, Erlangen, Germany) using a six-channel pelvic phased-array coil with capability of parallel imaging. Sequences included high resolution turbospin echo (TSE) T2-weighted imaging [repetition time (TR)/echo time (TE): 6,000-10,000 ms/136 ms, echo train length (ETL): 61, number of acquisitions: 3$]$ in the axial, coronal, and sagittal planes, and fat-suppressed spin echo T1-weighted imaging (740-790/19, number of acquisitions: 2) in the axial and sagittal plane, using a multislice technique. Slice thickness varied from 4 to $6 \mathrm{~mm}$ with a 0.8 - to $1.2-\mathrm{mm}$ interslice gap. Matrix size varied from $512 \times 435$ to $256 \times 144$ (the latter for T1-weighted images) and field of view (FOV) ranged from 350 to 400 . No intravenous contrast medium was used. The examinations were performed during the menstrual period if possible.

In four patients, additional DWI was performed, using a single-shot echo-planner imaging (EPI) sequence $(4,100 \mathrm{~ms} /$ $82 \mathrm{~ms}$, number of acquisitions: 4), FOV $350 \mathrm{~cm}$, matrix $192 \times 192$, slice thickness $4 \mathrm{~mm}$, interslice gap $0 \mathrm{~mm}, b$ values of $50,400,800$, and $1,200 \mathrm{~s} / \mathrm{mm}^{2}$.

The total imaging time per patient was approximately 24 min. The added examination time of diffusion-weighted imaging was approximately $4 \mathrm{~min}$.

\section{Image analysis}

Abdominal wall lesions were analysed for location, size and appearance on T2-weighted and T1-weighted images with fat suppression. Diagnosis was made on the basis of cyclical symptoms relating to menstrual periods and MR imaging showing blood products within a focal lesion in the abdominal wall.
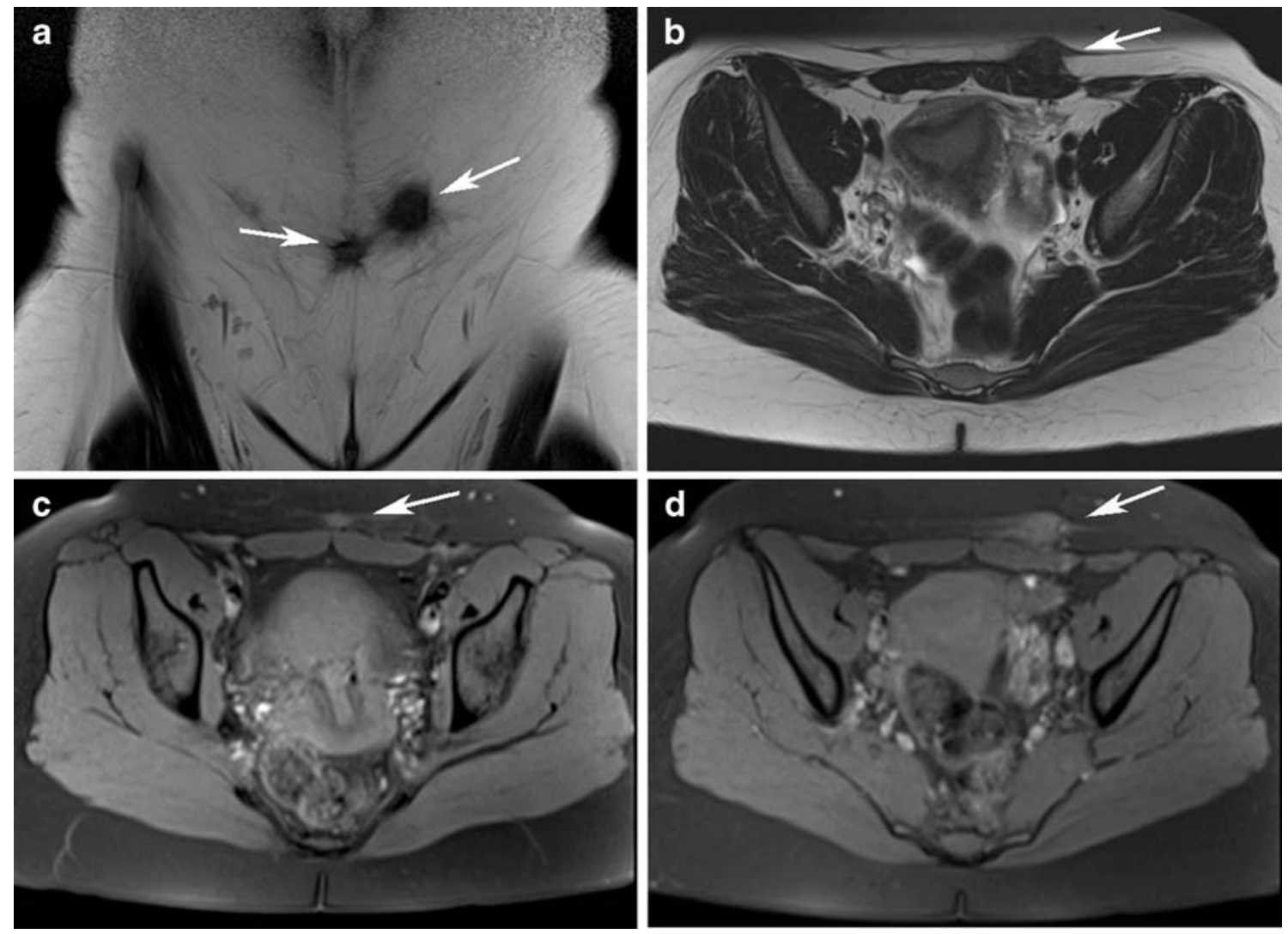

Fig. 1 AWE in a 28-year-old woman with a previous history of caesarean section, who presented with continuing cyclical pain symptoms after previous surgery elsewhere. a Coronal T2-weighted image shows two AWE lesions, in the left corner of the surgery scar

and more centrally. b Axial T2-weighted image shows AWE lesion ventrally from the rectus abdominis. c, d Axial T1-weighted images show slightly high intensity of AWE lesions compared with muscle 
For quantification of diffusion-weighted images, ADC values were calculated using $b$ values of 50, 400, 800 and $1,200 \mathrm{~s} / \mathrm{mm}^{2}$. A region of interest (ROI) of at least $30 \mathrm{~mm}^{2}$ was placed on the ADC map at the location of AWE. For the accurate location of the lesion, correlation with T2weighted images was used. MR examinations of all patients were also studied for other locations of deep infiltrating endometriosis, endometriomas, and adenomyosis.

\section{Results}

\section{Clinical analysis}

In almost all patients, AWE was clinically suspected or already diagnosed $(n=2$; hospital elsewhere). Most patients presented with cyclic pain symptoms of a lump located in the abdominal wall $(n=8)$. One patient, presenting with AWE in a herniation of the abdominal wall that developed after abdominal surgery, complained of continuous local pain. Another patient, treated previously with oral anticontraceptives (on a continuous basis) because of pelvic endometriosis had no pain symptoms at all. The patients' clinical characteristics are shown in Table 1.
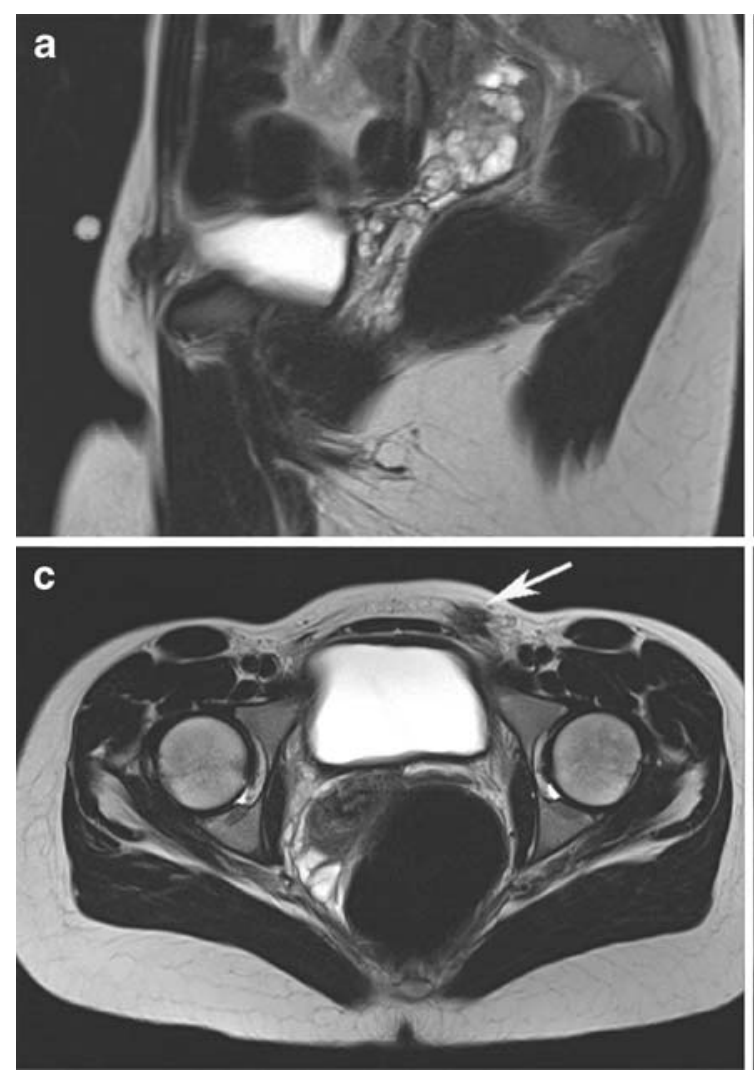

Fig. 2 AWE in a 21-year-old woman, without a previous history of surgery. a, c Sagittal and axial T2-weighted images show AWE lesion located ventrally and dorsally to the aponeurosis of the rectus obliques with isointense signal compared with muscle. b, d Sagittal

\section{MR imaging}

Twelve AWE lesions were found and analysed. Eight out of ten lesions were found at the corner site of the surgery scar. In the Pfannenstiel incision scars, four lesions were located in the left corner, two in the right corner and one (second lesion) more centrally (Fig. 1). The other lesions were found in the right corner of a trocar insertion scar, in the caudal corner of a median incision scar and more centrally in a hernia located in a median laparotomy scar. Two patients presented with spontaneous AWE located in the right and left groins, respectively (Fig. 2).

In most patients the lesion was located in the rectus abdominis $(n=5$; Fig. 3$)$ or ventrally or dorsally to the aponeurosis of the rectus oblique muscle $(n=6)$. In one extraordinary case, an endometriotic lesion, both cystic and solid, was located in a herniation of the abdominal wall (Fig. 4). The size of the lesions ranged from $16 \times 9 \mathrm{~mm}$ to $30 \times 17 \mathrm{~mm}$ in the axial plane and from $14 \mathrm{~mm}$ to $57 \mathrm{~mm}$ in the craniocaudal plane. The mean largest diameter in the axial plane was $24 \mathrm{~mm}$ and mean largest diameter in the craniocaudal plane was $27 \mathrm{~mm}$.

On T2-weighted MR imaging, AWE lesions showed isointense or hyperintense signal compared with muscle
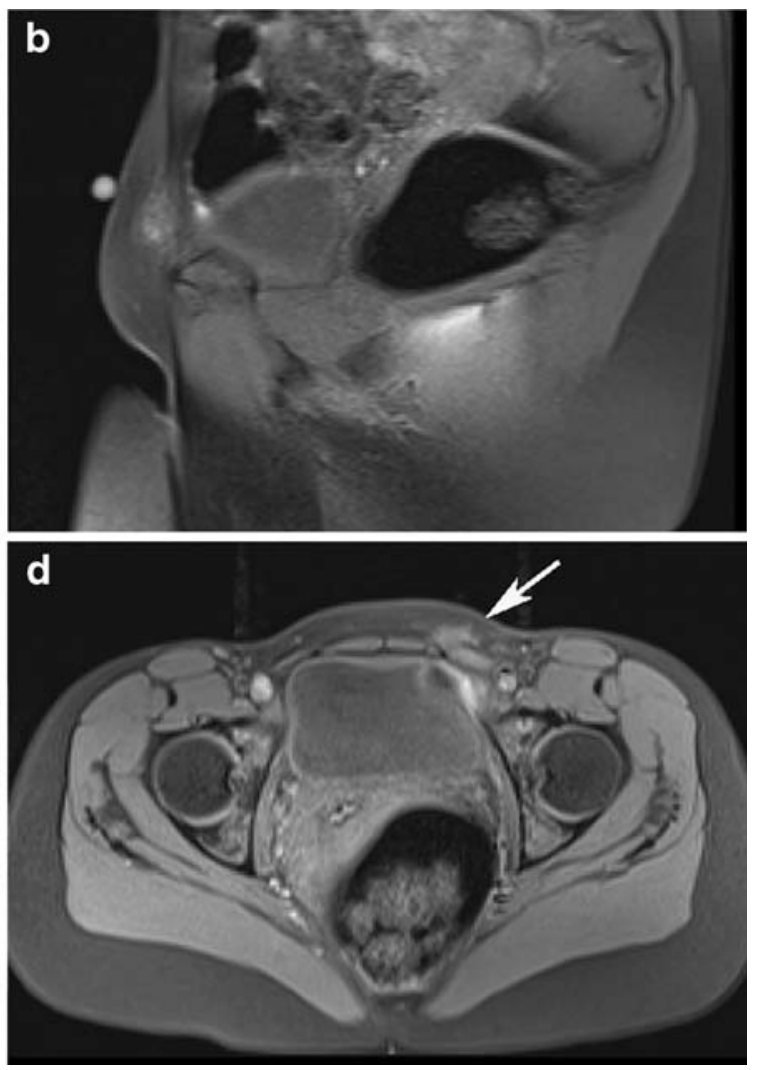

and axial T1-weighted images with fat suppression show isointense signal compared with muscle with small foci of high signal intensity, indicative of haemorrhage 

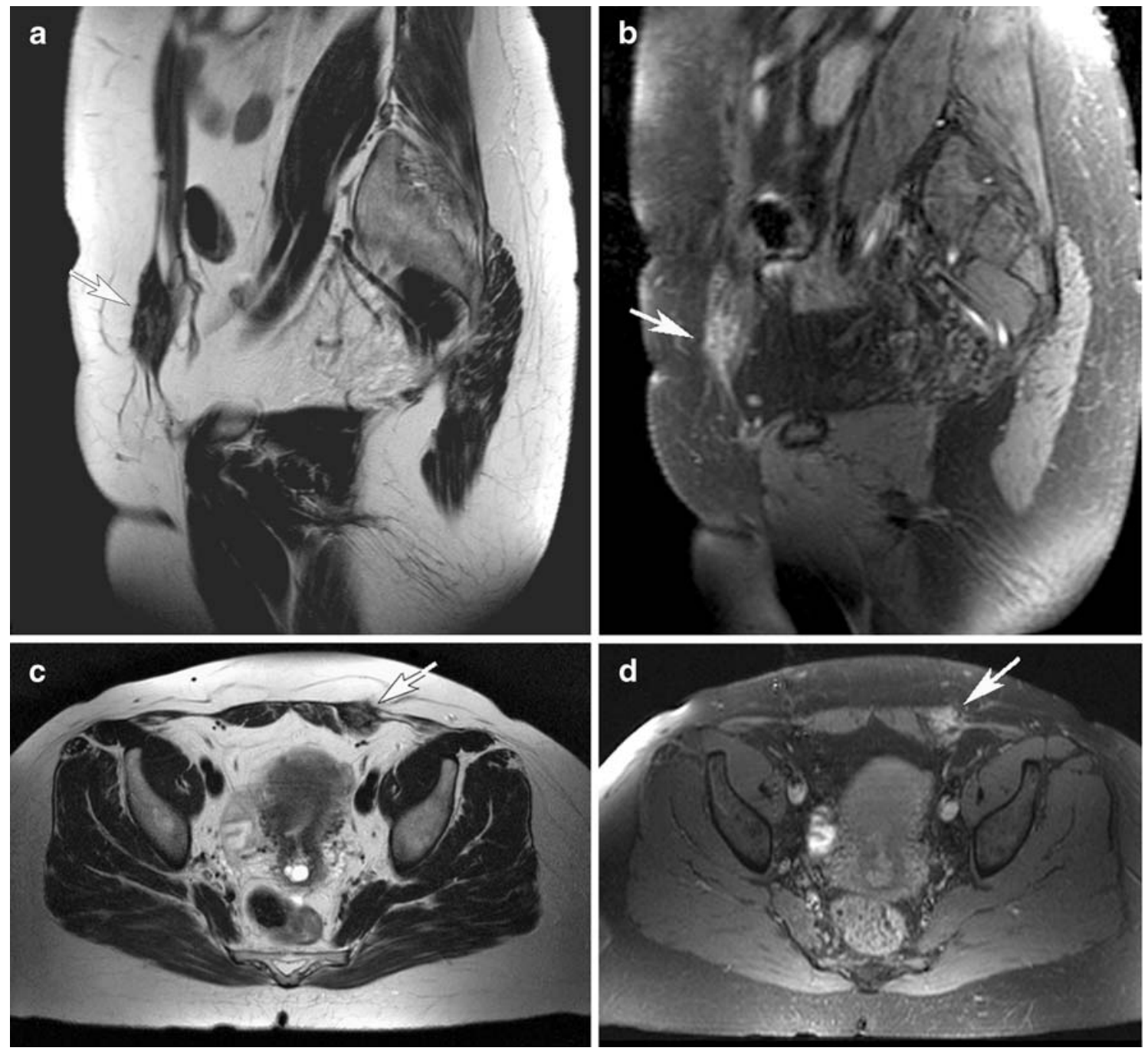

Fig. 3 Abdominal wall endometriosis (AWE) in a 40-year-old woman with a previous history of caesarean section (3). a, c Sagittal and axial T2-weighted images show AWE located in the rectus

abdominis muscle. b, d sagittal and axial T1-weighted images with fat suppression, show slightly hyperintense signal compared with muscle

with foci of high signal intensity in eight lesions. On T1weighted imaging with fat-suppression, lesions appeared isointense or slightly hyperintense compared with muscle, with small foci of high intensity in five lesions. Spontaneous AWE lesions did not appear different on MR imaging compared with AWE lesions located in surgery scars. Two surgery scar lesions contained large cystic components, showing homogeneously high signal intensity on T1-weighted imaging with fat saturation, indicative of haemorrhagic cysts (Fig. 5). In five patients, subsequent deep infiltrating endometriosis or adenomyosis was found (Table 2).

Mean ADC value of five AWE lesions was $0.93 \times 10^{-3}$ / $\mathrm{mm}^{2} / \mathrm{s}$ (range: $0.79 \times 10^{-3} / \mathrm{mm}^{2} / \mathrm{s}$ to $1.10 \times 10^{-3} / \mathrm{mm}^{2} / \mathrm{s}$ ). Diffusion-weighted images are shown in Fig. 6. These specific lesions did not show cystic components. ADC values of bladder endometriosis, endometriosis located at the fornix and adenomyosis showed ADC values of $0.57 \times$ $10^{-3} / \mathrm{mm}^{2} / \mathrm{s}, \quad 0.84 \times 10^{-3} / \mathrm{mm}^{2} / \mathrm{s}$ and $0.71 \times 10^{-3} / \mathrm{mm}^{2} / \mathrm{s}$, respectively.

\section{Discussion}

We presented 12 cases of AWE in ten patients. Almost all lesions showed a more typical appearance of endometriotic lesions on T2-weighted and T1-weighted fat-suppressed images; including an iso- to slightly hyperintense signal with or without small foci of high signal intensity. On the T1-weighted images with fat suppression these foci of high signal intensity are assumed to correlate with small haemorrhages. Absence of these hyperintense lesions might be caused by hormonal treatment [23]. In two patients a cystic hyperintense lesion was found on the 

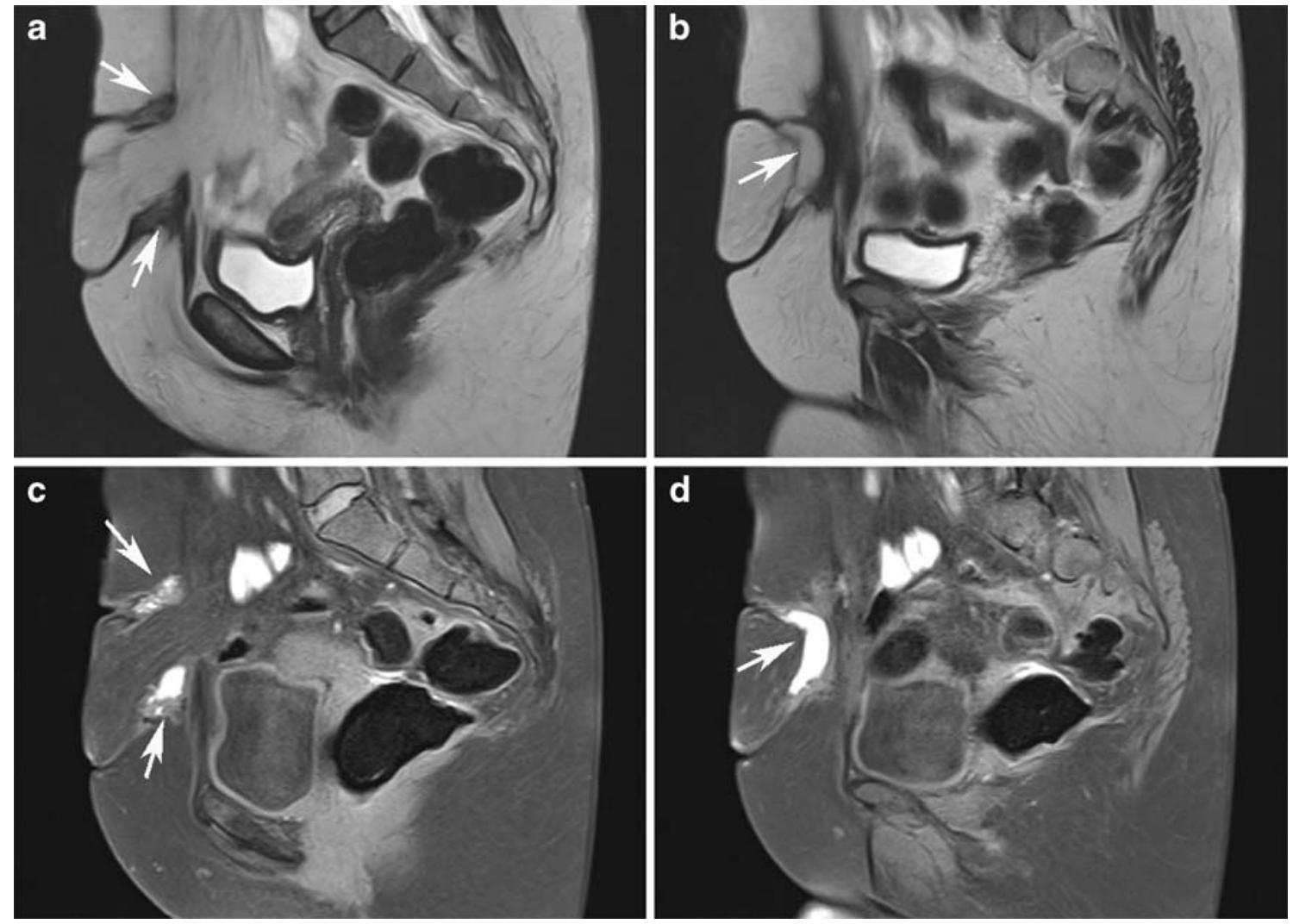

Fig. 4 AWE in a 36-year-old woman, with a previous history of a laparotomy (median incision), because of chronic appendicular inflammation. a, b Sagittal T2-weighted images show a herniation of the abdominal wall with omental fat tissue bulging through, reaching the subcutaneous layer of the skin. Surrounding the

herniation, extensive tissue, appearing as endometriosis, was found, with part of it located in the rectus abdominis. Moreover it shows a cystic lesion on the left lateral side of the herniation (b). c, d Sagittal T1-weighted images with fat suppression show the bloody contents of the cystic lesion

T1-weighted images (including shading on T2), suggesting endometriotic cysts in the lesions.

In four patients (five lesions) additional DWI was obtained. The mean ADC value of AWE was decreased $\left(0.93 \times 10^{-3} / \mathrm{mm}^{2} / \mathrm{s}\right)$. In the cystic part of one AWE lesion the ADC value was higher $\left(1.42 \times 10^{-3} / \mathrm{mm}^{2} / \mathrm{s}\right)$. This is comparable with previous reports on ADC values in endometrial cysts $[19,21]$. In endometrial cysts the age of blood influences the viscosity [24] and may therefore influence the ADC value. DIE located at the bladder wall and fornix posterior as well as adenomyosis showed lower $\mathrm{ADC}$ values. An explanation for the higher ADC values in most AWE lesions compared with ADC values in DIE may be that restricted diffusion is mainly caused by a high cellular density of the lesions and less by fibrotic tissue and smooth muscle hyperplasia. ADC values may help to diagnose AWE, although more studies are needed to confirm this. In a previous study, ADC values in desmoid tumours (range: $1.2-1.9 \times 10^{-3} / \mathrm{mm}^{2} / \mathrm{s}$ ) and nodular fasciitis (1.1 and $\left.2.3 \times 10^{-3} / \mathrm{mm}^{2} / \mathrm{s}\right)$ [25] were higher compared to ADC values in AWE. However, in most patients, nodular fasciitis or desmoid tumours are excluded from the

differential diagnosis, because in general these patients do not present with a mass in or close to a scar, pain symptoms during menstruation or continuous pain symptoms [26], as patients in our study did. Because of small numbers of patients and no earlier studies published regarding ADC values in DIE, also more studies should be performed to assess the value of DWI in differentiating DIE from other pathologies.

Scar endometriosis is thought to result from iatrogenic implantation of endometrium or endometriotic tissue during abdominal surgery. In our study, most cases of AWE were found at the corner site of the surgery scar (eight out of ten lesions). The reason for a predilection of AWE in corner sites of surgery scars is unknown. Although it could be related to the technical aspects of surgery and, in particular, the methods of suturing, we found no evidence of a predilection for scar endometriosis at the right or left corner, as previously reported by Teng et al. [27] They reported that endometriosis in a Pfannenstiel incision scar was found more often at the right corner of the surgery scar $(68 \%)$, possibly because of the predominance of operators standing on their patient's right side during surgery and 

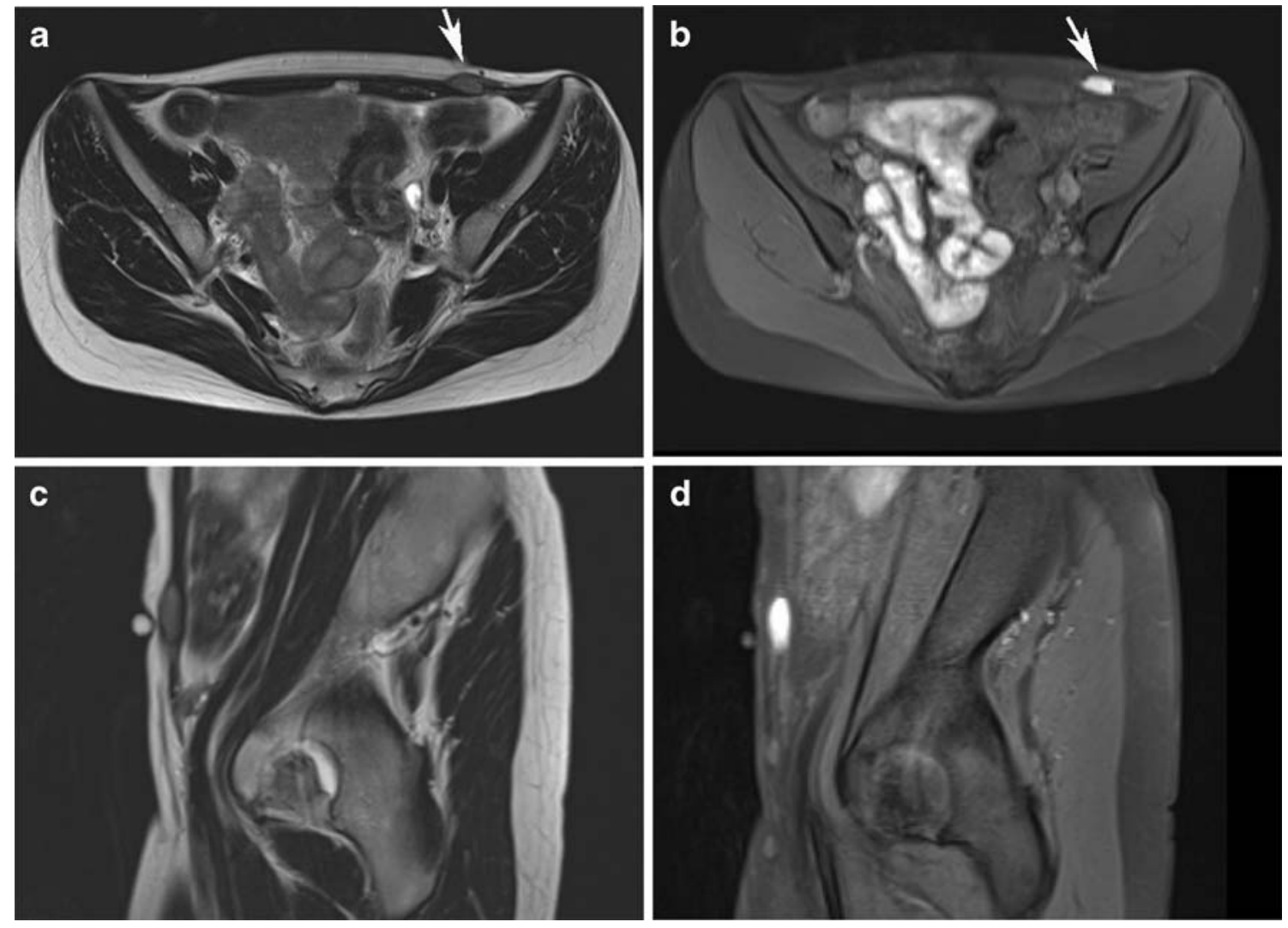

Fig. 5 AWE in a 30-year-old woman with a previous history of a laparotomical cystectomy of the right ovary (Pfannenstiel incision), because of endometriosis. a, c Axial and sagittal T2-weighted images show a completely homogeneous AWE lesion with inter-

endometrial inoculums not being easily found and removed on that side. In our study, the surgeons involved did not show a preferred table position, when asked.

The mechanisms involved in the pathogenesis of AWE without previous surgery is largely unknown. Theories reported earlier are haematogenic or lymphogenic dissemination of endometriosis cells from the abdominal cavity and metaplasia [11]. Moreover, spontaneous endometriosis located in the inguinal region is thought to develop from direct extension from pre-existing endome- mediate signal intensity located ventrally from the aponeurosis rectus obliques. b, d Axial and sagittal T1-weighted images with fat suppression show a homogeneous AWE lesion with high signal intensity, indicating a haemorrhagic cyst

triosis along the round ligament [28]. This mechanism may also have played a role in our two patients with spontaneous AWE lesions.

In our study one patient presented with endometriosis located in the wall of a hernia that developed after abdominal surgery (chronic inflammation or irritation of the appendix). Endometrial tissue may possibly be transported to the extra peritoneal space, facilitated by a herniation of intraabdominal tissue through the abdominal wall. However, it is not clear whether or not deep endometriosis located at the

Table 2 Subsequent pelvic endometriosis and adenomyosis

\begin{tabular}{lllll}
\hline $\begin{array}{l}\text { Patient (correlating } \\
\text { to Table 1) }\end{array}$ & $\begin{array}{l}\text { Retrocervical } \\
\text { endometriosis }\end{array}$ & $\begin{array}{l}\text { Bladder detrusor } \\
\text { endometriosis }\end{array}$ & $\begin{array}{l}\text { Endometriosis infiltrating } \\
\text { the bowel }\end{array}$ & $\begin{array}{l}\text { Endometriotic } \\
\text { ovarian cysts }\end{array}$ \\
\hline 1 & $\mathrm{x}$ & $\mathrm{x}$ & & $\begin{array}{l}\text { Adenomyosis } \\
2\end{array}$ \\
4 & $\mathrm{x}$ & $\mathrm{x}$ & & $\mathrm{x}$ \\
5 & $\mathrm{x}$ & $\mathrm{x}$ & \\
9 & $\mathrm{x}$ & & & $\mathrm{x}$ \\
\hline
\end{tabular}



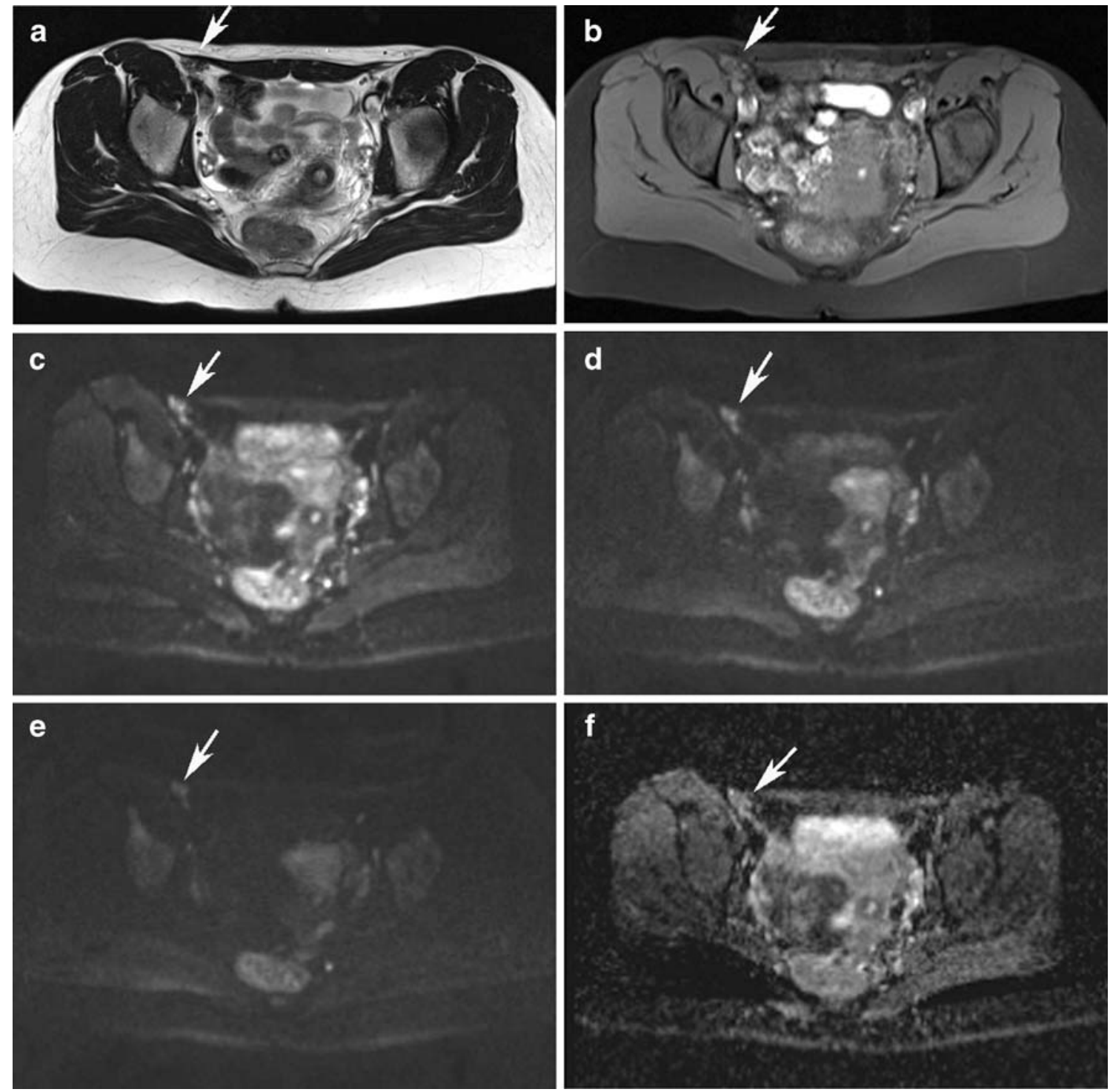

Fig. 6 Abdominal wall endometriosis (AWE) in a 31-year-old woman without a previous history of surgery. a Axial T2-weighted image shows a heterogeneous lesion located dorsally to the aponeurosis of the rectus oblique muscle. b Axial T1-weighted image with

fat suppression shows isointense signal of the lesion. c-e Diffusionweighted images ( $b$ values of 50,400 and $800 \mathrm{~s} / \mathrm{mm}^{2}$ ). f ADC map; the calculated ADC value of the AWE lesion is $0.93 \times 10^{-3} \mathrm{~mm}^{2} / \mathrm{s}$ (obtained with $b$ values of 50, 400, 800 and 1,200 s/mm²)

appendix was responsible for the complaints (no information about surgery in 1986), favouring the iatrogenic implantation route.

Depending on the site and size of AWE, treatment options include hormonal therapy and surgery. Hormonal treatment may help to reduce symptoms, but recurrence is common after discontinuation of treatment [15]. The recurrence rate after surgery reported in the previous literature is $4.3 \%$ [2]. To avoid recurrence, wide excision is recommended. Size of the lesion and extent of the mass, especially when it involves the rectus abdominis muscle or peritoneum, have shown to be risk factors for recurrence [11]. Recently, radiofrequency ablation (RFA) has been used as a new treatment for AWE.

RFA, used in a patient who refused surgical intervention, effectively reduced pain symptoms. More data are needed in order to make any recommendations [29].

MR imaging has become a useful tool in DIE to provide a roadmap to surgery. Previously MR accurately predicted deep infiltrating endometriosis [30]. Onbas et al. [14] demonstrated that contrast-enhanced dynamic MR imaging (DMI) in a small number of patients $(n=8)$ with suspected AWE may support its diagnosis, based on the similar vascularity of endometriomas and endometrial tissue. However, no other pathological conditions were present in their patient population. In our study MR imaging, performed because of clinical suspicion of AWE, confirmed the 
diagnosis and showed the relation of AWE to the rectus abdominis and the aponeurosis of the rectus oblique muscle. In cases of suspected AWE, preoperative MR imaging may be useful to determine the location and depth of infiltration in surrounding tissues. This to inform the surgeon which layer of the abdominal wall should be operated on and often even more extensively. The scan protocol we recommend to diagnose AWE includes T2-weighted and T1-weighted fat suppressed imaging in at least two planes. We did not use intravenous contrast, as previous studies demonstrated enhancement of AWE lesions on post-contrast T1-weighted images was not specific [7, 31-33].

Contrary to a previous study in which no higher predilection for pelvic endometriosis $(13 \%)$ was found in AWE, $46 \%$ of our patients showed subsequent pelvic endometriosis or adenomyosis on MR imaging [2]. This might be due to a bias of patients with deep infiltrating endometriosis at our hospital, which is a tertiary referral centre for endometriosis in The Netherlands.

In conclusion, AWE should be suspected in any female patient with cyclical pain from a mass in scar tissue, an abdominal hernia or the inguinal region. Depending on the size and site of the lesion treatment options are hormonal therapy or wide excision. MR might be a useful imaging technique to determine the location and depth of infiltration into surrounding tissue preoperatively. More studies are needed to assess the value of DWI in deep infiltrating endometriosis.

Open Access This article is distributed under the terms of the Creative Commons Attribution Noncommercial License which permits any noncommercial use, distribution, and reproduction in any medium, provided the original author(s) and source are credited.

\section{References}

1. Balleyguier C, Chapron C, Chopin N, Helenon O, Menu Y (2003) Abdominal wall and surgical scar endometriosis: results of magnetic resonance imaging. Gynecol Obstet Investig 55:220-224

2. Horton JD, Dezee KJ, Ahnfeldt EP, Wagner M (2008) Abdominal wall endometriosis: a surgeon's perspective and review of 445 cases. Am J Surg 196:207-212

3. Bats AS, Zafrani Y, Pautier P, Duvillard P, Morice P (2008) Malignant transformation of abdominal wall endometriosis to clear cell carcinoma: case report and review of the literature. Fertil Steril 90(4):1197.e13-1197.e16

4. Chene G, Darcha C, Dechelotte P, Mage G, Canis M (2007) Malignant degeneration of perineal endometriosis in episiotomy scar, case report and review of the literature. Int J Gynecol Cancer 17:709-714

5. Leng J, Lang J, Guo L, Li H, Liu Z (2006) Carcinosarcoma arising from atypical endometriosis in a cesarean section scar. Int J Gynecol Cancer 16:432-435

6. Matter M, Schneider N, McKee T (2003) Cystadenocarcinoma of the abdominal wall following caesarean section: case report and review of the literature. Gynecol Oncol 91:438-443

7. Hensen JH, Van B V, Puylaert JB (2006) Abdominal wall endometriosis: clinical presentation and imaging features with emphasis on sonography. AJR Am J Roentgenol 186:616-620
8. Gupta RK (2008) Fine-needle aspiration cytodiagnosis of endometriosis in cesarean section scar and rectus sheath mass lesions - a study of seven cases. Diagn Cytopathol 36:224-226

9. Pathan SK, Kapila K, Haji BE, Mallik MK, Al-Ansary TA, George SS et al (2005) Cytomorphological spectrum in scar endometriosis: a study of eight cases. Cytopathology 16:94-99

10. Koger KE, Shatney CH, Hodge K, McClenathan JH (1993) Surgical scar endometrioma. Surg Gynecol Obstet 177:243-246

11. Zhao X, Lang J, Leng J, Liu Z, Sun D, Zhu L (2005) Abdominal wall endometriomas. Int J Gynaecol Obstet 90:218-222

12. Singh M, Sivanesan K, Ghani R, Granger K (2009) Caesarean scar endometriosis. Arch Gynecol Obstet 279:217-219

13. Dwivedi AJ, Agrawal SN, Silva YJ (2002) Abdominal wall endometriomas. Dig Dis Sci 47:456-461

14. Onbas O, Kantarci M, Alper F, Kumtepe Y, Durur I, Ingec M et al (2007) Nodular endometriosis: dynamic MR imaging. Abdom Imaging 32:451-456

15. Pados G, Tympanidis J, Zafrakas M, Athanatos D, Bontis JN (2008) Ultrasound and MR-imaging in preoperative evaluation of two rare cases of scar endometriosis. Cases J 1:97

16. Wolf GC, Kopecky KK (1989) MR imaging of endometriosis arising in cesarean section scar. J Comput Assist Tomogr 13:150-152

17. Yu CY, Perez-Reyes M, Brown JJ, Borrello JA (1994) MR appearance of umbilical endometriosis. J Comput Assist Tomogr 18:269-271
18. Yamashita Y, Tang Y, Takahashi M (1998) Ultrafast MR imaging of the abdomen: echo planar imaging and diffusion-weighted imaging. J Magn Reson Imaging 8:367-374

19. Katayama M, Masui T, Kobayashi S, Ito T, Sakahara H, Nozaki A et al (2002) Diffusion-weighted echo planar imaging of ovarian tumors: is it useful to measure apparent diffusion coefficients? J Comput Assist Tomogr 26:250-256

20. Moteki T, Ishizaka H (2000) Diffusionweighted EPI of cystic ovarian lesions: evaluation of cystic contents using apparent diffusion coefficients. J Magn Reson Imaging 12:1014-1019

21. Nakayama T, Yoshimitsu K, Irie $H$, Aibe H, Tajima T, Nishie A et al (2005) Diffusion-weighted echo-planar MR imaging and ADC mapping in the differential diagnosis of ovarian cystic masses: usefulness of detecting keratinoid substances in mature cystic teratomas. J Magn Reson Imaging 22:271-278

22. Fujii S, Kakite S, Nishihara K, Kanasaki Y, Harada T, Kigawa J et al (2008) Diagnostic accuracy of diffusion-weighted imaging in differentiating benign from malignant ovarian lesions. J Magn Reson Imaging 28:1149-1156

23. Imaoka I, Ascher SM, Sugimura K, Takahashi K, Li H, Cuomo F et al (2002) MR imaging of diffuse adenomyosis changes after GnRH analog therapy. J Magn Reson Imaging $15: 285-290$ 
24. Takahashi K, Okada S, Okada M, Kitao M, Kaji Y, Sugimura K (1996)

Magnetic resonance relaxation time in evaluating the cyst fluid characteristics of endometrioma. Hum Reprod 11:857-860

25. Einarsdottir H, Karlsson M, Wejde J, Bauer HC (2004) Diffusion-weighted MRI of soft tissue tumours. Eur Radiol 14:959-963

26. Grobmyer SR, Knapik JA, Foss RM, Copeland EM, Hochwald SN (2009) Nodular fasciitis: differential considerations and current management strategies. Am Surg 75:610-614
27. Teng CC, Yang HM, Chen KF, Yang CJ, Chen LS, Kuo CL (2008) Abdominal wall endometriosis: an overlooked but possibly preventable complication. Taiwan J Obstet Gynecol 47:42-48

28. Tokue H, Tsushima Y, Endo K (2009) Magnetic resonance imaging findings of extrapelvic endometriosis of the round ligament. Jpn J Radiol 27:45-47

29. Carrafiello G, Fontana F, Pellegrino C, Mangini M, Cabrini L, Mariani D et al (2009) Radiofrequency ablation of abdominal wall endometrioma. Cardiovasc Interv Radiol. doi:10.1007/ s00270-008-9500-8

30. Bazot M, Darai E, Hourani R, Thomassin I, Cortez A, Uzan S et al (2004) Deep pelvic endometriosis: MR imaging for diagnosis and prediction of extension of disease. Radiology 232:379-389
31. Cervini P, Mahoney J, Wu L (2005) Endometriosis in the canal of Nuck: atypical manifestations in an unusual location. AJR Am J Roentgenol 85:284-285

32. Keyserling HF, Castillo M, Smith JK (2003) Cranial fasciitis of childhood. AJNR Am J Neuroradiol 24:14651467

33. Dinauer PA, Brixey CJ, Moncur JT, Fanburg-Smith JC, Murphey MD (2007) Pathologic and MR imaging features of benign fibrous soft-tissue tumors in adults. Radiographics 27:173-187 